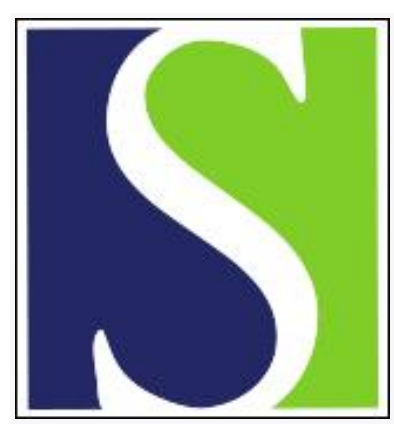

Scand J Work Environ Health 1986;12(3):223

https://doi.org/10.5271/sjweh.2153

Issue date: Jun 1986

Bronchial asthma due to exposure to potassium aluminumtetrafluoride.

by Hjortsberg U, Nise G, Orbaek P, Soes-Petersen U, Arborelius M Jr

Refers to the following text of the Journal: 1984;10(3):189-195

This article in PubMed: www.ncbi.nlm.nih.gov/pubmed/3749838

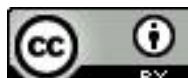




\section{Bronchial asthma due to exposure to potassium aluminumtetrafluoride}

We would like to point out an occupational risk related to exposure to potassium aluminumtetrafluoride. We have observed an increased number of cases of bronchial asthma and bronchial hyperreactivity among workers exposed to this aluminum salt. At an assembly plant aluminumfluoride salt was used as a flux for soldering aluminum. The particle size of the flux was in the respirable fraction, all being below $10 \mu \mathrm{m}$. Aluminum parts were dipped in water containing a suspension of aluminumfluoride salt. After drying, the parts covered with potassium aluminumtetrafluoride flux were assembled by the workers. Hygienic measurements showed low total dust levels. The time-weighted average for respirable dust was around $1 \mathrm{mg} / \mathrm{m}^{3}$, being one-fifth of the current Swedish occupational standard for respirable dust $\left(5 \mathrm{mg} / \mathrm{m}^{3}\right)$. Seven out of 14 workers were in daily contact with the aluminumfluoride compound. Five of these seven workers have developed clinical bronchial asthma and/or bronchial hyperreactivity. Two of these workers had their bronchial hyperreactivity tested before and after provocation with the aluminumfluoride flux. They showed increased hyperreactivity at least some weeks after the provocation.

Bronchial asthma and asthmatic bronchitis has been described in the aluminum producing industry (1). It is generally known among workers as potroom asthma. It has however been difficult to pinpoint a specific causative agent. Irritating gases such as sulfur dioxide and fluoric acid and other irritating fumes are present in the industry, as well as aluminumfluoride compounds. Sodium aluminumtetrafluoride, used in the primary aluminum industry, produces small respirable fibers. These fibers are so small that they deposit in small airways (2).

Nocturnal asthma has been described in a large Swedish factory producing aluminumfluoride. Exposure levels varied but were sometimes high. In a follow-up the workers' bronchial hyperreactivity did not improve after the exposure was terminated (3).

Two of our patients gave a history of subjective improvement after being removed from further exposure to the aluminumfluoride salt. Yet repeated metacholine provocation tests failed to show improvement in their hyperreactivity. It is plausible that prolonged exposure has induced a permanent state of bronchial hyperreactivity, even if the role played by their continued smoking is, in this respect, hard to evaluate. Provocation with aluminumfluoride flux failed to provoke an early asthmatic reaction. There was however a late reaction and their bronchial hyperreactivity increased. So far we have not seen any positive skin reactions to aluminumfluoride salt. These observations suggest that the asthmatic reaction is nonimmunologic.

The slowly progressive increase of bronchial hyperreactivity and its tendency to become permanent is a problem. Since the asthmatic reaction might be slight, exposed workers will try to minimize their breathing difficulties. Once hyperreactivity has developed, any irritation to bronchial airways will cause bronchospasm.

The industrial production of aluminumfluoride salt is substantial, and no current hygienic standard has been set for potassium aluminumtetrafluoride. The asthma-producing property is connected to the salt since similar hyperreactivity response has been seen after exposure to aluminumsulfate (3). We want to point out this type of asthma and bronchial hyperreactivity so that further action might be taken to reduce exposure levels and set a specific occupational standard. We suggest an occupational standard of well below $1 \mathrm{mg} / \mathrm{m}^{3}$ for respirable dust of potassium aluminumtetrafluoride salt. Industries using this aluminumfluoride powder should also introduce regular check-ups of their employees for the detection of hyperreactivity. A provocation test using metacholine might be suitable for that purpose.

\section{References}

1. Chan-Yeung M, Wong R, Maclean L, Tan F, Schulzer M, Enarson D, Martin A, Dennis R, Grzybowski S. Epidemiologic health study of workers in an aluminum smelter in British Columbia. Am Rev Respir Dis 127 (1983) $465-469$.

2. Gylseth B, Björseth O, Dugstad Ö, Gjönnes J. Occurrence of fibrous sodium aluminumtetrafluoride particles in potrooms of the primary aluminum industry. Scand $\mathrm{J}$ Work Environ Health 10 (1984) 189-195.

3. Simonsson BG, Sjöberg A, Rolf C, Haeger-Aronsen B. Acute and long-term airway hyperreactivity in aluminumsalt exposed workers with nocturnal asthma. Eur J Respir Dis 66 (1985) 105-118.

Ulf Hjortsberg, MD, Gun Nise, MSc, Palle Ørbæk, MD, Ulrik Søes-Petersen, MD, Måns Arborelius Jr, MD

Malmö General Hospital

S-21401 Malmö Sweden 